Article

\title{
Efficiency of Public Service Delivery-A Post-ICT Deployment Analysis
}

\author{
Mudalige Uthpala Indeelinie Alahakoon and Shahzadah Nayyar Jehan * \\ Tohoku University of Community Service and Science, Tsuruoka 997-0035, Japan; g619001@gs.koeki-u.ac.jp \\ * Correspondence: jehan@koeki-u.ac.jp
}

Received: 10 September 2020; Accepted: 4 November 2020; Published: 10 November 2020

\begin{abstract}
Since 2000, Sri Lanka has embarked upon a path towards digitalization of most of the government functions and the process of public service delivery in the country. The process started with several disjointed initiatives culminating by 2010 into a full-scale program funded by many international donors around the world. Digital promotion agencies such as the Information Communication Technology Authority (ICTA) and infrastructure development entities such as the Lanka Government Network (LGN) were established, and the process significantly picked up pace in various government agencies and departments. This process, sometimes called e-governance, was set into motion to improve the efficiency of the government operations and public service delivery at all governmental levels. A decade has passed since many primary public services underwent a digital transformation. In this paper, we analyze the digital governance process and assess the efficiency status of public services in the country. We conducted an output-oriented, nonparametric analysis of the performance data by applying data envelopment analysis (DEA). The data were collected through a questionnaire-based field survey. Our findings suggest that most public services have not achieved optimal efficiency levels, and there is still plenty to be achieved by performance enhancement measures that have been adopted by the various agencies of the Sri Lankan government.
\end{abstract}

Keywords: information communication technology; public service; Sri Lanka; technological change

JEL Classification: O31; O310; O360; O380

\section{Introduction}

The advent of the Internet opened collaborative opportunities for businesses and governments around the world. By the end of the last millennium, internet technology had become commonplace, well within reach of ordinary individuals. This phenomenon had two significant outcomes in the arena of public service delivery, i.e., increased awareness of individual rights and higher expectations from public services. Utilization of information and communication technology (ICT) by developed countries started early on, and many studies found positive outcomes of using ICT in public services. The positive results were not limited to service providers only-the public in general benefited from digital services too. The use of ICT resulted in better information dissemination, in addition to enhancing the efficiency of public service delivery in many countries that opted for public service transformation. Many studies have been conducted to evaluate the role of ICT in promoting the efficiency of public services. Findings of such studies support our initial observations in this regard.

The introduction of ICT into public services in developing economies, on the other hand, lagged both in time and scale. Lack of knowledge, training, initiatives, and resources are usually mentioned as reasons for the delayed introduction of digital transformation in developing economies. The spread of the Internet and social media among the general populace of developing countries happened before the same technological wave hit the public sectors and government agencies in 
general. The spread of information and greater access to worldwide knowledge resources, in turn, prompted a greater demand for better and efficient public services in these countries. Sri Lanka is a case in point where this transformation was delayed for a long time. However, in the early years of this millennium, a greater demand for better services gained momentum, and a push for the digital transformation of all government operations and public services came to the forefront of reform efforts in the country. Many international donor agencies and governments came to aid these efforts. They provided substantial funds to introduce and execute large-scale digital transformation of the government operations and the services provided. The Sri Lankan government started the e-Sri Lanka (ESL) project in 2002, and in 2003, the Information Communication Technology Authority (ICTA) was established, in addition to the establishment of the Lanka Government Network (LGN). With these developments, the digital transformation process thoroughly took place throughout the ministries and departments of the Sri Lankan government. The drive towards e-governance was set into motion to improve the efficiency of the government operations and improve public service delivery at all governmental levels.

Chen and Hsieh (2014) note that despite many pitfalls, it is correct to state that the digitalization of public services can lead to better public service policies and better services. They contend that this is due to newer technologies that allow big data processing in a better and faster manner. Hence, as Bhatnagar (2014) also noted, a better-informed policy making and service delivery can take place. There is no doubt that digitalization in public services is both encouraged as well as loathed, as it is inevitable that the process comes with both pros and cons. The positive side is better information and consequent efficiency in the PSD. On the flip side, however, most governments are criticized for acting as a big brother as they further invade the private space of the public with big data analytics. Such analytics are not always used altruistically by the governments as Linkov et al. (2018) noticed in their treatise on government strategies for sustainable digital governance. However, as our motive in this study is not to test the altruistic or villainous nature of digital governance, we will depart from that discussion here and move on to the operational consequences of the use of ICT into PSD. It is the operations and the resultant efficiency in the PSD that we are concerned with in this paper. While there are plenty of arguments for and against the specificity of results that should be expected from the introduction of ICT into PSD, nevertheless, the studies that correlate ICT and PSD are far more numerous and provide reasonable assurance that these two are related. Von Hayek (1945) has extensively elaborated on the nature such transformations into governance and has explained how and when digital governance can go awry and why one must be very careful in assessing the cause and effect relationship thereof. In a later and relatively recent study, Von Hayek (1989) warns that making such transformations on the pretense of knowledge of citizens' needs may be a fallacy and lead to undesirable consequences.

We noticed that ICT initiatives in PSD in Sri Lanka started without much understanding of the citizens' needs, as there is hardly any documentary evidence to suggest this. The country did not have a concept or infrastructure of big data before the launch of the ESL initiative; rather, it can be termed as a precursor of a big data system in the country. More recently, ICTA and the United Nations Development Programme (UNDP) in Sri Lanka signed a 4-year memorandum of understanding to support Sri Lanka's aspirations for digital transformation. This program focuses particularly on the digital transformation of the public sector, along with re-engineering processes to ensure effective digital deployment. It may also be noted that LGN and ESL started almost simultaneously, and this meant the introduction of ICT into PSD without much assessment of the operational or citizens' needs. It is thus apparent that whatever transformation has taken place in this period is mostly disconnected with the results expected from such reforms. We, therefore, undertook this study from ground up and conducted an extensive survey about the results of this digital transformation to fill the gap that is there, i.e., whether ICT usage in the governance in Sri Lanka has resulted in improving PSD, and to what extent. We can list our research questions as follows: 
- To what extent has the operational efficiency been achieved with ICT deployment in 20 D\&Ms (D\&Ms) of the government of Sri Lanka?

- To what extent has informational efficiency increased with the ICT deployment in the D\&Ms?

- To what extent has PSD efficiency increased in a post-ICT deployment scenario in the country?

\section{Literature}

There are numerous studies published over time that affirm the utility of ICT into governance. Such studies highlight the use of ICT in explaining the pros and cons thereof. ICT has been found to help in information dissemination, improving PSD, improving transparency and facilitating greater citizen participation. Bhatnagar (2009) has carried out an extensive study and explained the potential of e-governance for both large-scale and small-scale projects. Gurbaxani and Whang (1991) stated that the use of ICT resolves agency issues by addressing the asymmetry in information provision and is thus desirable.

Regarding the use of ICT in PSD, the United Nations Public Administration Network (UNPAN) survey (UN 2012) emphasized the importance of governance rethinking in an e-government framework while continuing with PSD. Some other studies have focused on the technical aspects of the ICT in PSD. Averweg (2012) stressed upon the importance of connectivity and bandwidth of ICT infrastructure while truncating discussion on its relationship with PSD. Bhatnagar (2009) emphasized the importance of consulting all stakeholders, especially the citizens, for whose benefit the ICT is deployed. Jansen (2012) indicates a mismatch between the functions implicit in the stated objectives for eGovernment and the way ICT is deployed; the mismatch can, at least partly, be attributed to an inadequate understanding of ICT and its many functions.

The mismatch between the stated objectives and the actual deployment can both be devastating as well as costly. This mismatch can obviously be a result of the knowledge gap that arises due to misunderstanding or not fully understanding the final objectives of the system, i.e., catering to the citizens' needs. In theory, taxpayer money is spent on the provision and reformation of public services. Thus, people are naturally inclined to know the rationale of spending on such services. Similarly, people would like to be sure of the propriety of such spending, i.e., whether money is allocated directly in proportion to the services provided by the government or not. In the case of Sri Lanka, though a significant amount of funds to introduce e-governance and related ICT regimes has come from international donor agencies, a large amount of investment has been allocated from the public exchequer in approximately the last ten years. Therefore, an assessment should be made regarding how performance has improved with the changes due to ICT deployment. The success of reform and spending will improve public confidence in such measures and the related expenditure. Korneta (2019) stresses that it is crucial to justify the value of such services in public perception in order to allow continued support for investments into technologies. Zheng (2017) observed with ample evidence that improvement in service delivery is considered an important performance indicator of e-governance. While many studies have been conducted on e-administration, the efficiency of ICT regimes in post-implementation scenarios has not been explored. Del Sordo et al. (2017) observe that it is also a fact that the concept of e-governance, especially in the context of developing countries, is relatively new and not fully understood. An earlier study of the efficiency of public services in Sri Lanka conducted by ICTA (2008) found that in public perception, most public services in Sri Lanka are not efficient. Now, more than a decade has passed since these strenuous efforts were first made, and investment was poured into this ICT regime. It is thus essential to assess the value of investment into ICT and find out where the public services stand in terms of efficiency. A study by Moore (1995) have found that the effectiveness and the efficiency of public services enhance the value of services in public perception. Alford and O'flynn (2009) argue that it is highly essential to also provide a framework for service evaluation. Jehan et al. (2010a) presented a transformational view of the change management that may be a caused by introduction of ICT in Sri Lanka's PSD. In a later study Jehan et al. (2010b) presented a practical framework in which change management can be incorporated 
in the organization of certain public service departments of Sri Lanka. Elapatha and Jehan (2020) conducted a study about the efficiency of PSD in a post BPR implementation scenario in Sri Lanka. Such studies may explain to some extent about the background of our study, however, those studies do not overlap the scope of our study and are entirely different in the approach and the findings.

\section{Data and Methodology}

\subsection{Data}

The data were collected through a field survey conducted in the summer of 2020 during February and March. In total, we studied 20 representative departments and ministries (after this referred to as entities) of the government of Sri Lanka, where the ICT regime was implemented for ten years since 2010 (Table 1). Data on the efficiency or inefficiency of the public service delivery after the ICT implementation were collected on a 5-point Likert scale. Twenty questionnaires were distributed and collected from each of the 20 entities. In total, 400 responses were collected. Originally, the questionnaire was designed in English and then translated into Sinhala language, one of the major official languages of Sri Lanka, to assure ease of understandability and response to the questions. The responses were sought on a Likert scale: $5=$ strong agreement, $4=$ agreement, $3=$ neutral, $2=$ disagreement, and 1 = strong disagreement. The questionnaire was comprised of 40 questions divided into ICT input measures and ICT performance-related output questions. Output questions were classified into three categories: service efficiency (OP1), informational efficiency (OP2), and operational efficiency (OP3). As we were interested in assessing output efficiency, we took output orientation in our analysis, as we were interested in knowing the efficacy of inputs through the outcomes. It seems relevant that we explain three output response variables briefly. The questions in the OP1 category were related to various aspects of PSD services in the respondents' respective entities. OP1 refers to the extent to which the ICT deployment has increased the service efficiency of the entities. Service efficiency refers to how PSD handling improved as a result of ICT implementation, and reflects the time and ease with which a client was dealt with after a specific public service was requested. Informational efficiency (OP2) is in relation to the ease with which information flow took place both vertically and horizontally across the whole PSD system. Operational efficiency (OP3) entails a decrease in the time and effort exerted by the employees after the implementation of such measures. The questions in this category were related to the impact of ICT in making the flow of information accumulation, handling and processing in a post-implementation scenario.

Table 1. Data and questionnaire structure.

\begin{tabular}{cccccc}
\hline \multirow{2}{*}{ No. of Questions } & \multicolumn{5}{c}{ Response } \\
\cline { 2 - 6 } & Strongly Agree & Agree & Neutral & Disagree & Strongly Disagree \\
\hline Input Questions $(1,2,3 \ldots, 20)$ & 5 & 4 & 3 & 2 & 1 \\
Outcome Questions $(1,2,3 \ldots, 20)$ & 5 & 4 & 3 & 2 & 1 \\
\hline Total Questions 40 & \multicolumn{5}{c}{ Total responses 400} \\
\hline
\end{tabular}

In Table 2, the departments and ministries, each allotted an entity number from 1 to 20, are listed. The input average column gives the average response of all 20 respondents from that entity. The last three columns show the average response to each output question put to the respondents from each organization. 
Table 2. Input and output data.

\begin{tabular}{|c|c|c|c|c|c|}
\hline \multirow{2}{*}{ Department/Ministry } & \multirow{2}{*}{ Entity No. } & \multicolumn{4}{|c|}{ Input/Output Data } \\
\hline & & Input Avg. & OP11 Avg. & OP2 Avg. & OP3 Avg. \\
\hline Department of Immigration and Emigration & E1 & 3.620 & 3.830 & 3.830 & 3.630 \\
\hline Department of Register of Persons & E2 & 3.540 & 3.540 & 3.780 & 3.460 \\
\hline Department of Import and Export & E3 & 3.700 & 3.710 & 3.850 & 3.610 \\
\hline Department of Examination & E4 & 3.720 & 3.800 & 3.840 & 3.760 \\
\hline Department of Customs & E5 & 3.430 & 3.480 & 3.640 & 3.410 \\
\hline Department of Motor Traffic & E6 & 3.190 & 3.740 & 3.440 & 3.140 \\
\hline Department of Registrar General & E7 & 3.730 & 3.810 & 3.850 & 3.720 \\
\hline Department of Pension & E8 & 3.900 & 3.860 & 4.120 & 3.780 \\
\hline Department of Fisheries & E9 & 3.670 & 3.710 & 4.020 & 3.510 \\
\hline Department of Railway & E10 & 3.600 & 3.950 & 3.760 & 3.750 \\
\hline Department of Labor & E11 & 3.390 & 3.690 & 3.660 & 3.500 \\
\hline Ministry of Education & E12 & 3.310 & 3.460 & 3.640 & 3.310 \\
\hline Ministry of Healthcare & E13 & 3.810 & 3.930 & 4.050 & 3.710 \\
\hline Election Commission & E14 & 3.630 & 3.820 & 3.810 & 3.730 \\
\hline Police Commission & E15 & 3.490 & 3.700 & 3.560 & 3.610 \\
\hline Foreign Bureau & E16 & 3.890 & 4.010 & 4.010 & 3.960 \\
\hline Electricity Board & E17 & 3.420 & 3.640 & 3.480 & 3.480 \\
\hline Central Bank & E18 & 3.690 & 3.880 & 3.950 & 3.520 \\
\hline National Transport Commission & E19 & 3.660 & 3.940 & 3.930 & 3.650 \\
\hline Ministry of Foreign Affairs & E20 & 3.560 & 4.000 & 3.810 & 3.280 \\
\hline
\end{tabular}

\subsection{Methodology}

In this paper, we have applied a nonparametric multistage data envelopment analysis (DEA) to understand how the ICT regime performed. The three outputs factors (OP1, OP2, and Op3) were used in the analysis, and the technical efficiency (TE) was measured on a variable returns to scale (VRTS) from an output orientation. Making use of standard VRTS and DEA models, we assumed output orientation as the magnitude, and the direction of input has already been defined and is not alterable in the short-run (Fare et al. 1994). Thus, only outputs, i.e., services, information, and operations, can be adjusted to allow our entities to optimally perform in order to achieve maximum efficiency levels. Farrell (1957) originally developed these efficiency measures; however, over time, DEA has evolved as a body of knowledge and technique. We also relied on the work of Charnes et al. (1976) and on that of Farrell (1957) regarding efficiency measurement models. The efficiency assessment model presented by Charnes et al. is commonly referred to as the Charnes, Cooper and Rhodes (CCR) model, hence the use of the term CCR model in this paper. Using the CCR model, we carried out a detailed assessment of the historical performance of the public service delivery system in Sri Lanka after the implementation of the ICT regime. Charnes et al. (1991) demonstrates that DEA is a useful and robust approach to assess historical performance. Our decision to use output orientation allows us to compute the extent to which output quantities may be altered without making any changes to the input quantities.

The CCR model defines the efficiency of a decision-making unit (DMU) as the maximum of a ratio of weighted outputs to weighted inputs, subject to the condition that the similar ratios for every DMU can be less than or equal to unity (Färe and Grosskopf 2005). The CCR model can be presented with mathematical programming methods, as later suggested by both Boles (1967) and Afriat (1972). As we are proposing to use a variable returns-to-scale technical efficiency (VRTS) measure, we will start from a constant returns to scale (CRTS) CCR model in the linear programming form and then introduce convexity constraint to adapt it for VRTS.

Given the constant returns-to-scale constraint, our goal is to maximize efficiency, i.e., to maximize output (y) divided by input (x) subjected to weight vectors $\mathrm{u}^{\prime}$ for outputs and $\mathrm{v}^{\prime}$ for inputs (Farrell 1957). Hence, our goal is to

$$
\max _{\mathrm{u}, \mathrm{v}}\left(\frac{\mathrm{u}^{\prime} \mathrm{y}_{\mathrm{i}}}{\mathrm{v}^{\prime} \mathrm{x}_{\mathrm{i}}}\right),
$$


subject to

$$
\begin{gathered}
\left(\frac{u^{\prime} y_{j}}{v^{\prime} x_{j}}\right) \leq 1, j=1,2, \ldots, N \\
u, v \geq 0
\end{gathered}
$$

Imposing the constraint $\mathrm{v}^{\prime} \mathrm{x}_{\mathrm{i}}=1$ (to avoid infinite solutions problem)

We obtain

$$
\max _{\mathrm{u}, \mathrm{v}}\left(\mu^{\prime} \mathrm{y}_{\mathrm{i}}\right)
$$

subject to

$$
\begin{gathered}
v^{\prime} x_{i}=1, \\
\mu^{\prime} y_{j}-v^{\prime} x_{j} \leq 0, j=1,2, \ldots, N, \\
\mu, v \geq 0,
\end{gathered}
$$

Here, $\mu$ and $v$, instead of $u$ and $v$, represent transformation into the multiplier form of linear programming. At this point, the CCR model proposes to introduce duality in linear programming to derive the following envelopment form:

$$
\min _{\Theta, \lambda} \Theta
$$

subject to

$$
\begin{gathered}
-\mathrm{y}_{\mathrm{i}}+\mathrm{Y} \lambda \geq 0, \\
\Theta \mathrm{x}_{\mathrm{i}}-\mathrm{X} \lambda \geq 0, \\
\lambda \geq 0,
\end{gathered}
$$

Here, $\theta$ is a scalar, and $\lambda$ is an Nx1 vector of constants (Farrell 1957).

Finally, the CCR model introduces the convexity constraint $N 1^{\prime} \lambda=1$ to (3) to introduce VRS as (Charnes et al. 1976).

$$
\min _{\Theta \lambda} \Theta
$$

subject to

$$
\begin{gathered}
-\mathrm{y}_{\mathrm{i}}+\mathrm{Y} \lambda \geq 0, \\
\Theta \mathrm{x}_{\mathrm{i}}-\mathrm{X} \lambda \geq 1 \\
\mathrm{~N} 1^{\prime} \lambda=1 \\
\lambda \geq 1
\end{gathered}
$$

Thus, we obtain the VRTS version of the CCR model, which can work under the constraints as stipulated in the equations above and provide a reliable measure of the efficiency of entities covered in this study. Using DEAP version 2.0, we can calculate not only efficiency per se, but peers, peer targets and slacks amongst our entities.

\section{Results}

Based on the VRTS CCR model presented in the earlier section, we ran our data through DEAP version 2.0 for DEA and calculated efficiency measures, peer entities, targets and slacks for our data set of 20 entities. The results can be categorized and summarized as presented in the next subsections.

\subsection{Efficiency Results}

The results tabulated in Table 3 present efficiency results both on CRTS as well as on VRTS, but as per our scheme mentioned earlier in the Methodology Section, we will be focusing mostly on the VRST results. However, we can see that moving from CRTS to VRTS, we have a better insight into the TE measure for our entities. On CRTS, only four entities, i.e., entities with TE $=1$, are on the efficient level; however, with VRTS, half of the entities are on the efficient level; with the scale adjusted, E6, E10, E11, and E12 are at the efficient level with CRTS (-). We also note that E15 and E17 have increasing reruns to scale (IRS) and can improve their performance by increasing the level of operations and services. They should do so until they have achieved the optimum scale. All other entities have decreasing 
returns to scale (DRS) situations, and there is a need for capacity building in order to improve service efficiency. In short, other than those entities with TE $=1$ and a scale efficiency of 1 , all other entities with $\mathrm{TE}<1$ have room for improvement either by changing the scale upwards or downwards. In order to do more, we may need to look at the peer situation, which we will discuss in the next subsection.

Table 3. Efficiency Results.

\begin{tabular}{ccccc}
\hline \multirow{2}{*}{ Entity No. } & \multicolumn{4}{c}{ Efficiency Results Summary } \\
\cline { 2 - 5 } & CRTS & VRTS & Scale & Returns to Scale \\
\hline E1 & 0.977 & 0.992 & 0.985 & DRS \\
E2 & 0.973 & 0.983 & 0.990 & DRS \\
E3 & 0.957 & 0.976 & 0.981 & DRS \\
E4 & 0.974 & 0.988 & 0.986 & DRS \\
E5 & 0.976 & 0.979 & 0.997 & DRS \\
E6 & 1 & 1 & 1 & - \\
E7 & 0.964 & 0.982 & 0.981 & DRS \\
E8 & 0.964 & 1 & 0.964 & DRS \\
E9 & 0.996 & 1 & 0.996 & DRS \\
E10 & 1 & 1 & 1 & - \\
E11 & 1 & 1 & 1 & - \\
E12 & 1 & 1 & 1 & - \\
E13 & 0.971 & 1 & 0.971 & DRS \\
E14 & 0.990 & 0.998 & 0.992 & DRS \\
E15 & 0.993 & 0.998 & 0.995 & IRS \\
E16 & 0.979 & 1 & 0.979 & DRS \\
E17 & 0.977 & 0.984 & 0.992 & IRS \\
E18 & 0.978 & 0.995 & 0.982 & DRS \\
E19 & 0.988 & 1 & DRS \\
E20 & 0.987 & 1 & DRS \\
Means & 0.982 & 0.994 & 0.988 & \\
\hline
\end{tabular}

\subsection{Peer Analysis}

Table 4 reflects the peer situation to show which entities can serve as a benchmark for other entities to mimic their performance and achieve a higher level of efficiency. E11 and E19 stand out at the benchmark as they are peers to most other entities, i.e., E11 is a peer to eight other entities, and E19 is a peer to five other entities, followed by E9 and E10, which are peers to four other groups. Peer analysis is useful to understand how another entity in the peer group takes weight in a particular entity. Adjusting the performance in conjunction with the benchmarking peer will steer the lagging entity to move towards better efficiency levels. It should be noted that the underlying assumption regarding weights is that the limit we imposed on the VRS CCR model is maintained here too, i.e., $\mathrm{t} \Sigma \lambda=1$ (meaning that the sum of peer weights does not exceed 1).

\subsection{Target Analysis}

In Table 5, we present input, output, and overall output targets for all of our 20 entities analyzed in this study. Target analysis allows us to compare and ascertain difference between the actual performance levels achieved and the projected targets that should have been achieved. Here, we have target inputs and output for all 20 entities. We should observe that entities with steady superior efficiency scores across various efficiency measures only pursue the target scores with relatively smaller differences. Most of the entities have some target differences, suggesting room for improvement in performance. The improvement can be achieved either by decreasing the level of inputs or by increasing the level of outputs. 
Table 4. Peer analysis.

\begin{tabular}{|c|c|c|c|c|c|c|c|}
\hline \multirow{3}{*}{$\begin{array}{c}\text { Entity No. } \\
\text { E1 }\end{array}$} & \multicolumn{7}{|c|}{ Peer and Peer Weight Analysis } \\
\hline & \multicolumn{3}{|c|}{ Summary of Peers (Entity No.) } & \multicolumn{3}{|c|}{ Summary of Peers' Weights } & \multirow{2}{*}{$\begin{array}{c}\text { Peer Count } \\
0\end{array}$} \\
\hline & 19 & 16 & 11 & 0.515 & 0.182 & 0.303 & \\
\hline E2 & 19 & 9 & 11 & 0.101 & 0.438 & 0.461 & 0 \\
\hline E3 & 16 & 9 & 19 & 0.173 & 0.025 & 0.802 & 0 \\
\hline $\mathrm{E} 4$ & 16 & 11 & 10 & 0.634 & 0.304 & 0.062 & 0 \\
\hline E5 & 9 & 11 & 12 & 0.169 & 0.738 & 0.093 & 0 \\
\hline E6 & 6 & & & 1.000 & & & 0 \\
\hline E7 & 16 & 11 & 19 & 0.538 & 0.199 & 0.263 & 0 \\
\hline E8 & 8 & & & 1.000 & & & 0 \\
\hline E9 & 9 & & & 1.000 & & & 4 \\
\hline E10 & 10 & & & 1.000 & & & 4 \\
\hline E11 & 11 & & & 1.000 & & & 8 \\
\hline E12 & 12 & & & 1.000 & & & 1 \\
\hline E13 & 13 & & & 1.000 & & & 1 \\
\hline E14 & 16 & 11 & 10 & 0.370 & 0.369 & 0.261 & 0 \\
\hline E15 & 11 & 10 & & 0.524 & 0.476 & & 0 \\
\hline E16 & 16 & & & 1.000 & & & 5 \\
\hline E17 & 11 & 10 & & 0.857 & 0.143 & & 0 \\
\hline E18 & 13 & 19 & 9 & 0.188 & 0.637 & 0.174 & 0 \\
\hline E19 & 19 & & & 1.000 & & & 5 \\
\hline E20 & 20 & & & 1.000 & & & 0 \\
\hline
\end{tabular}

Table 5. Target analysis.

\begin{tabular}{cccccc}
\hline & \multicolumn{3}{c}{ Target Analysis } \\
\cline { 2 - 4 } Entity No. & \multicolumn{3}{c}{ Output Targets } & Overall OP Targets & Input Targets \\
\cline { 2 - 4 } & OP1 & OP2 & OP3 & 3.801 & 3.620 \\
E1 & 3.877 & 3.863 & 3.661 & 3.695 & 3.540 \\
E2 & 3.724 & 3.845 & 3.520 & 3.863 & 3.700 \\
E3 & 3.946 & 3.946 & 3.700 & 3.867 & 3.720 \\
E4 & 3.909 & 3.888 & 3.807 & 3.626 & 3.430 \\
E5 & 3.672 & 3.719 & 3.484 & 3.440 & 3.190 \\
E6 & 3.740 & 3.440 & 3.140 & 3.877 & 3.730 \\
E7 & 3.928 & 3.919 & 3.787 & 3.920 & 3.900 \\
E8 & 3.860 & 4.120 & 3.780 & 3.740 & 3.670 \\
E9 & 3.710 & 4.020 & 3.510 & 3.820 & 3.600 \\
E10 & 3.950 & 3.760 & 3.750 & 3.620 & 3.390 \\
E11 & 3.690 & 3.660 & 3.500 & 3.470 & 3.310 \\
E12 & 3.460 & 3.640 & 3.310 & 3.890 & 3.810 \\
E13 & 3.930 & 4.050 & 3.710 & 3.809 & 3.630 \\
E14 & 3.876 & 3.816 & 3.736 & 3.715 & 3.490 \\
E15 & 3.814 & 3.708 & 3.619 & 3.990 & 3.890 \\
E16 & 4.010 & 4.010 & 3.960 & 3.649 & 3.420 \\
E17 & 3.727 & 3.674 & 3.536 & 3.832 & 3.690 \\
E18 & 3.898 & 3.968 & 3.637 & 3.840 & 3.660 \\
E19 & 3.940 & 3.930 & 3.650 & 3.690 & 3.560 \\
E20 & 4.000 & 3.810 & 3.280 & & \\
\hline
\end{tabular}

\subsection{Slacks Analysis}

Analyzing slacks under the DEA approach of frontier construction may not be convenient for both calculation and interpretation, and many researchers also maintain that this significance of the slacks is exaggerated (Coelli 1996). In our slack analysis (Table 6), we see that there are no input slacks. However, we note several output slacks; most of them are OP1 slacks, i.e., output related to efficiency 
in the data. In principle, any non-zero slacks should be noted and analyzed. It may be pertinent to note that output slacks will equal zero only if $Y \lambda-Y_{i}=0$ (Charnes et al. 1976). In short, we need to observe slacks from OP1 more closely, while there are not many slacks in the case on OP2 and OP3. Finally, our entities can be considered technically efficient if they are an efficient frontier and all related slacks are zero (Charnes et al. 1976).

Table 6. Slack analysis.

\begin{tabular}{cccccc}
\hline & \multicolumn{3}{c}{ Slack Analysis } \\
\cline { 2 - 4 } Entity No. & \multicolumn{3}{c}{ Output Slacks } & Overall OP Slacks & Input Slacks \\
\cline { 2 - 4 } & OP1 & OP2 & OP3 & 0.009 & 0.000 \\
E1 & 0.014 & 0.000 & 0.000 & 0.043 & 0.000 \\
E2 & 0.123 & 0.000 & 0.000 & 0.052 & 0.000 \\
E3 & 0.144 & 0.000 & 0.000 & 0.019 & 0.000 \\
E4 & 0.061 & 0.000 & 0.000 & 0.040 & 0.000 \\
E5 & 0.116 & 0.000 & 0.000 & 0.000 & 0.000 \\
E6 & 0.000 & 0.000 & 0.000 & 0.019 & 0.000 \\
E7 & 0.049 & 0.000 & 0.000 & 0.000 & 0.000 \\
E8 & 0.000 & 0.000 & 0.000 & 0.000 & 0.000 \\
E9 & 0.000 & 0.000 & 0.000 & 0.000 & 0.000 \\
E10 & 0.000 & 0.000 & 0.000 & 0.000 & 0.000 \\
E11 & 0.000 & 0.000 & 0.000 & 0.000 & 0.000 \\
E12 & 0.000 & 0.000 & 0.000 & 0.000 & 0.000 \\
E13 & 0.000 & 0.000 & 0.000 & 0.014 & 0.000 \\
E14 & 0.051 & 0.000 & 0.000 & 0.086 & 0.000 \\
E15 & 0.105 & 0.139 & 0.000 & 0.000 & 0.000 \\
E16 & 0.000 & 0.000 & 0.000 & 0.062 & 0.000 \\
E17 & 0.029 & 0.139 & 0.000 & 0.034 & 0.000 \\
E18 & 0.000 & 0.000 & 0.101 & 0.000 & 0.000 \\
E19 & 0.000 & 0.000 & 0.000 & 0.000 & 0.000 \\
E20 & 0.000 & 0.000 & 0.000 & 0.019 & 0.000 \\
Mean & 0.035 & 0.014 & 0.005 & &
\end{tabular}

\section{Discussion}

Sri Lanka is a lower-middle-income country with a per capita GDP of USD 3852 in 2019; the same was USD 4102 in 2018. After three decades of civil war that ended in 2009, the economy grew at an average of 5.3 per cent during the period of 2010-2019; however, the growth has slowed down in more recent years. After growing by 2.3 per cent in 2019, the economy contracted by 1.6 per cent year-on-year in the first quarter of 2020. According to the World Bank Report on Sri Lanka (2020), the country represents a success story in many ways and is making a steady transition towards a more competitive country. The UN Survey's (UN 2020) findings suggest that the country's transition towards digital governance is more noteworthy, as its e-governance digital index (EGDI) has been steadily improving over many years as depicted in the Figure 1. The EGDI shows an improvement in the country's e-governance ranking since 2012 followed by a more recent decline, which may be attributed to lingering political instability in the country since a couple of years ago.

Our research shows that deployment of ICT in the country has not been entirely smooth. The results of our study indicate disparate performance across the entities of the Sri Lankan government. We can identify benchmarks as well as slackers in the whole PSD structure through this study. We suggest that apparent incongruity of results across various PSD entities should be minimized to allow for a smoother ICT continuum resulting in a complete transformation of the PSD structure in the country. Chen (2003) suggests that the e-government initiative of a country progresses along an information-communication-transaction-transformation continuum (ICTT). In other words, the digital transformation can be regarded as the capability of a country to move along the aforementioned 4-stage 
ICTT continuum. We have, however, taken a 3-output factor (OP1, OP2, and OP3) approach towards performance assessment in this study; those three factors correspond to the first three factors of the ICTT continuum suggested by Chen. Fernando (2006) states that under limited resource conditions, we will need to improve performance in order to satisfy public expectation regarding public service delivery. Bonina and Cordella (2008) observed that when the public attaches a higher value to the use of ICT in governance, this leads to further developments and innovation. Castelnovo and Simonetta (2007) stressed this point even further in their paper where they proved that ICT, governance and public value are interconnected.

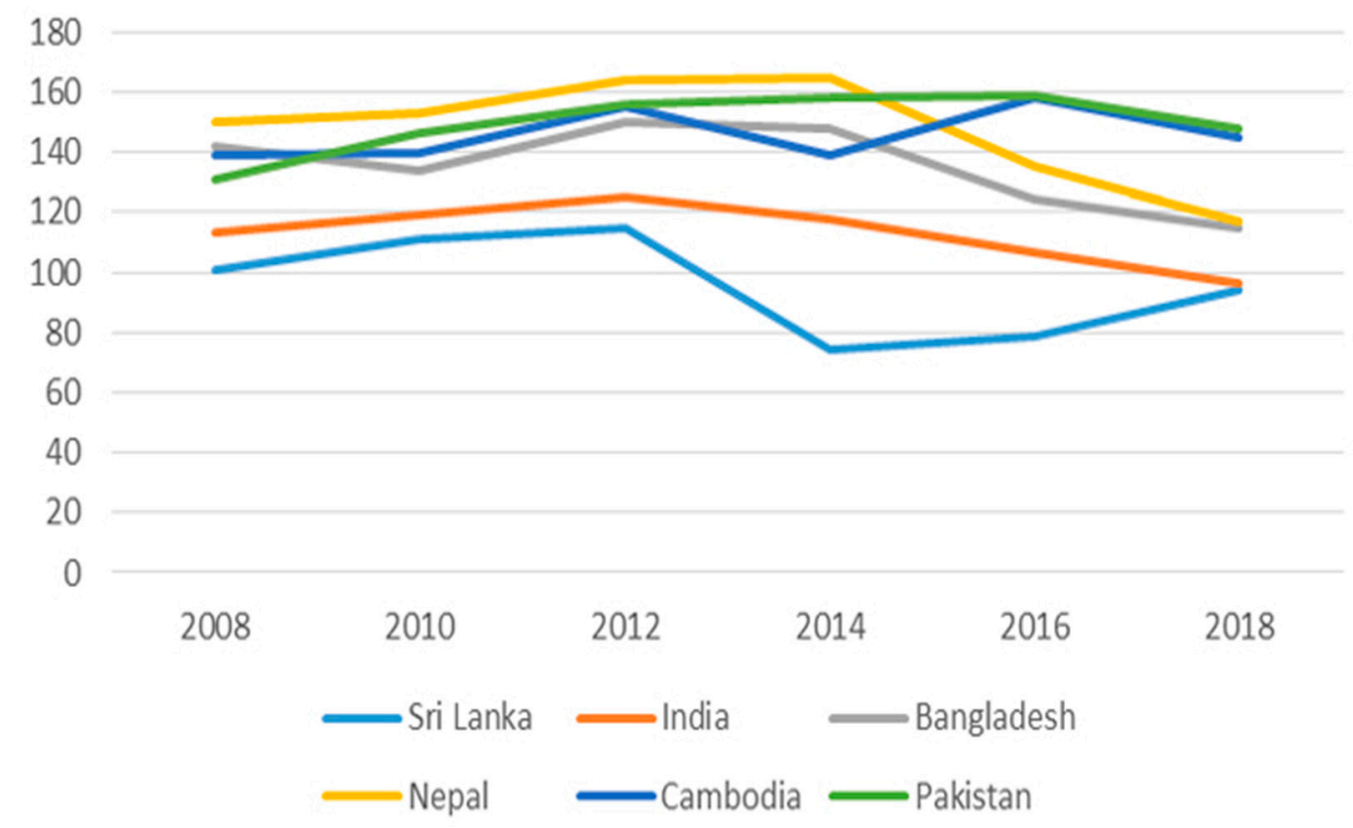

Figure 1. E-governance digital index (EGDI) ranks (lower is better). Source: UN e Government Database.

Consequently, we mapped out the performance of the public services in the wake of the ICT regime in three areas, i.e., services (OP1), information (OP2) and operations (OP3). Our findings suggest that OP1, i.e., the technical efficiency score regarding public service delivery, is not consistent across all entities. With a TE score of 0.957 (CRTS) and 0.976 (VRTS), service delivery at the Department of Imports and Exports (E3) has been the least inefficient area as compared to others. This suggests that while departments and ministries have benefited from the implementation of the ICT regime, the same cannot be said for the public service delivery efficiency across all of them. The situation becomes further apparent as we look at the returns to scale, where we noted that most departments and ministries are faced with decreasing returns-to-scale situations and would require a scale adjustment in order to improve their efficiency levels. There are few exceptions, such as E6, E10, E11, and E12 (the corresponding names of the departments or the ministries can be cross-checked in Table 1). The Department of Labor (E11) has come out as a star performer in a comparative analysis, with TE $=1$ and a constant returns-to-scale situation. It can serve as a peer to the highest number of other departments and ministries, which is eight in total. This result suggests that other entities should at least replicate the Department of Labor's performance per the peer weights given in Table 3. Furthermore, from a scalar perspective, the Department of Pensions (E8) has plenty of unused capacity and at the same time is facing a decreasing returns-to-scale situation. This situation may be indicative of a structural issue of the department, and the situation requires more in-depth insight in order to pinpoint the exact cause of the problem with the department.

We previously mentioned in the Methodology Section that we have taken an output orientation in conducting DEA. This orientation allows us to compute how many output quantities may be altered without making any changes to the input quantities. Thus, we can see that how much performance 
of each entity can be improved only by mimicking the performance of peers that lie at the efficiency frontier. At the same time, the level of inputs (components of the ICT regime) remains unaltered. It is essential to take this position, as we know that the ICT regime cannot be altered in the short run, but we can improve the efficiencies of our entities even with the current ICT regime in place. Input and output targets also indicate differences in the actual performance and the expected performance for each of the entities. We should be able to adjust actual performance by comparing it with the targets for all three outputs. We will restrict our comments to the output targets as we took an output orientation in our analysis. Additionally, we found that there are multiple slacks, especially in OP1, i.e., many entities can achieve a higher level of service delivery even at the present scale. Entities numbered E1-E5, E7, E14, E15, E17 and E20 have significant slacks, and a performance improvement regarding OP1 is possible after careful investigation of the underlying causes.

\section{Conclusions}

Evaluating a publicly funded project related to public service is very important in order to ensure continued investment in the project and also to ensure public support for such projects. E-governance project with a comprehensive ICT regime initiated with the support from many international donors, in addition to local funding, has never been assessed in the way carried out in this paper. The project started with a comprehensive field survey conducted right through the departments and ministries where the project was implemented, which provided us with excellent data to work with. Due diligence was applied to ensure the robustness of the data and balanced deployment of the questionnaire-based survey in order to gain meaningful and usable data. The results from the study portray the weaker areas of ICT deployment in the country, which, in turn, allows us to provide meaningful advice to the related entities for improving managerial performance. There is room for improvement both in managerial performance and ICT-related measures, i.e., service, information and operations. However, this also portrays a limitation of our analysis, as, while we can point out the weaknesses in ICT deployment in a geospatial manner, we can suggest the specific ICT-related measures that would require an improvement. This would require an analysis of the technical aspects of the ICT regime.

Furthermore, we would like to point out one more limitation of our study, that is, the fourth factor of ICTT continuum that we previously mentioned, i.e., transformation. We suppose an additional study with a different set of inquiry variables would be required to assess the degree of transformation in this ICT regime. Finally, we have presented a composite picture of the efficiency at various departments and ministries in the wake of the ICT regime implementation. Presenting each entity's performance data individually and explaining individual performances on a one-to-one basis could further extend the analysis. However, as we wanted to gain an overall picture of the situation after the ITC regime implementation, we will leave a detailed entity-wise performance analysis for a later study.

Author Contributions: Conceptualization, M.U.I.A. and S.N.J.; methodology, M.U.I.A.; formal analysis, M.U.I.A.; resources, M.U.I.A.; data curating, M.U.I.A.; writing—original draft preparation, M.U.I.A.; writing-review and editing, M.U.I.A. and S.N.J.; visualization, M.U.I.A.; supervision, S.N.J. All authors have read and agreed to the published version of the manuscript.

Funding: This research received no external funding.

Acknowledgments: The authors are deeply thankful to the functionaries of various departments and ministries of the government of Sri Lanka who assisted in the dissemination and collection of the questionnaire.

Conflicts of Interest: The authors declare no conflict of interest.

\section{References}

Afriat, Sidney N. 1972. Efficiency Estimation of Production Functions. International Economic Review 13: 568-98. [CrossRef]

Alford, John, and Janine O'flynn. 2009. Making Sense of Public Value: Concepts, Critiques and Emergent Meanings. International Journal of Public Administration 32: 171-91. [CrossRef] 
Averweg, Udo Richard. 2012. Linking Public Service Delivery and Technology in a Municipal Information Society in South Africa. Information Technology for Developing Countries 22: 8-12. Available online: http://deity.gov. in/sites/upload_files/dit/files/SocialMediaFrameworkDraftforPublicConsultation_192011.pdf (accessed on 1 November 2020).

Bhatnagar, Subhash. 2009. Unlocking E-Government Potential: Concepts, Cases and Practical Insights. New Delhi: Sage Publications India, pp. 52-60.

Bhatnagar, Subash. 2014. Public Service Delivery: Role of Information and Communication Technology in Improving Governance and Development Impact, Asian Development Bank. License: CC BY 3.0 IGO. Available online: http://hdl.handle.net/11540/4206 (accessed on 30 October 2020).

Boles, James N. 1967. Efficiency squared-efficient computation of efficiency indexes. Paper presented at Western Farm Economic Association Proceedings, Pullman, WA, USA, July; pp. 137-42.

Bonina, Carla M., and Antonio Cordella. 2008. The new public management, e-government and the notion of public value: Lessons from Mexico. Paper presented at SIG GlobDev's First Annual Workshop, Paris, France, December 13.

Castelnovo, Walter, and Massimo Simonetta. 2007. The public value evaluation of e-government policies. The Electronic Journal of Information System Evaluation 11: 61-72.

Charnes, A., W. W. Cooper, and E. Rhodes. 1976. Exposition Interpretation and Extensions of Farrell Efficiency Measures. Unpublished paper. April 30.

Charnes, Abraham, W. W. Cooper, and Robert M. Thrall. 1991. A structure for classifying and characterizing efficiency and inefficiency in data development analysis. Journal of Productivity Analysis 2: 197-237. [CrossRef]

Chen, Hsinchun. 2003. Digital government: Technologies and practices. Decision Support Systems 34: 223-27. [CrossRef]

Chen, Yu-Che, and Tsui-Chuan Hsieh. 2014. Big Data for Digital Government. International Journal of Public Administration in the Digital Age (IJPADA) 1: 1-14. [CrossRef]

Coelli, Tim. 1996. A Guide to DEAP Version 2.1: A Data Envelopment Analysis (Computer) Program. CEPA Working Papers No.8/96. Armidale: CEPA, Deptt. of Economtrics, University of New England.

Del Sordo, Carlotta, Rebecca L. Orelli, and Emanuele Padovani. 2017. Governing the public sector e- performance: The accounting practices in the digital age. In Decision Management: Concepts, Methodologies, Tools, and Applications. Hershey: IGI Global.

Elapatha, Vishakha Wijeratne, and Shahzadah Nayyar Jehan. 2020. An Analysis of the implementation of business process re- engineering in public services. Journal of Open Innovation: Technology, Market, and Complexity 6: 114. [CrossRef]

Färe, Rolf, and Shawna Grosskopf. 2005. Nonparametric tests of regularity, Farrell efficiency, and goodness-of-fit. Journal of Econometrics 6: 415-25. [CrossRef]

Fare, Rolf, Rolf Färe, Rolf Fèare, Shawna Grosskopf, and CA Knox Lovell. 1994. Production Frontiers. Cambridge: Cambridge University Press.

Farrell, Michael James. 1957. The Measurement of Productive Efficiency. Series A (General). Journal of the Royal Statistical Society 120: 253-290. [CrossRef]

Fernando, R. Lalitha S. 2006. Managerial Innovation in Delivery Service in Public Sector Organizations in Sri Lanka. Edited by M. Salahuddin and S. Aminuzzaman. Dhaka: Shrabon Printing Press, pp. 221-37.

Gurbaxani, Vijay, and Seungjin Whang. 1991. The Impact of Information Systems on Organizations and Markets. Communications of the Association for Computing Machinery 34: 59-73. [CrossRef]

ICTA. 2008. Government Organizations Visitors' Survey, Information Communication Technology Agency of Sri Lanka, Colombo. Available online: www.icta.lk/ (accessed on 25 October 2020).

Jansen, Arild. 2012. The Understanding of ICTs in Public Sector and Its Impact on Governance. Paper presented at 11th International Conference on Electronic Government (EGOV), Kristiansand, Norway, September 3-6; pp. 174-86. [CrossRef]

Jehan, Shahzadah Nayyar, Gigurwa Gamage Duminda Nishantha, and Shahzadah Qamar Jehan. 2010a. E-governance initiative in Sri Lankan public service delivery. Paper presented at the 12th International Conference on Advanced CommunicationTechnology (ICACT), Gangwon-Do, Korea, February 7-10; pp. 1625-29. 
Jehan, Shahzadah Nayyar, Nishantha Gigurwa Gamage Duminda, and Uchida Yasuo. 2010b. BPR in large public organizations: A case of managing change in a developing country. Journal of Japan Association for Management Systems 27: 25-31.

Korneta, Piotr. 2019. Critical success factors for Polish agricultural distributors. British Food Journal 121: 1565-78. [CrossRef]

Linkov, Igor, Benjamin D. Trump, Kelsey Poinsatte-Jones, and Marie-Valentine Florin. 2018. Governance strategies for a sustainable digital world. Sustainability 10: 440. [CrossRef]

Moore, Mark Harrison. 1995. Creating Public Value: Strategic Management in Government. Cambridge: Harvard University Press.

UN. 2012. United Nations E-Government Survey: E-Government for the People. pp. 51-57. Available online: https://publicadministration.un.org/egovkb/Portals/egovkb/Documents/un/2012Survey/ unpan048065.pdf (accessed on 30 October 2020).

UN. 2020. United Nations E-Government Survey 2020: Digital Government in the Decade of Action for Sustainable Development (With addendum on COVID-19 Response). New York: UN. [CrossRef]

Von Hayek, Friedrich A. 1945. The Use of Knowledge in Society. The American Economic Review 35: 519-30.

Von Hayek, Friedrich A. 1989. The Pretense of Knowledge. The American Economic Review 79: 3-7.

World Bank Report on Sri Lanka. 2020. Available online: https://www.worldbank.org/en/country/srilanka (accessed on 30 October 2020).

Zheng, Yueping. 2017. Explaining Citizens' E-Participation Usage: Functionality of E-Participation Applications. Administration \& Society 49: 423-42.

Publisher's Note: MDPI stays neutral with regard to jurisdictional claims in published maps and institutional affiliations.

(C) 2020 by the authors. Licensee MDPI, Basel, Switzerland. This article is an open access article distributed under the terms and conditions of the Creative Commons Attribution (CC BY) license (http://creativecommons.org/licenses/by/4.0/). 